\title{
Chlamydia pneumoniae in atheroma: consideration of criteria for causality
}

\author{
Allan Shor, James I Phillips, Gloria Ong, Brenda J Thomas, David Taylor-Robinson
}

\begin{abstract}
Aims-(1) To seek evidence of the existence of Chlamydia pneumoniae in a spectrum of atheromatous lesions in different types of arteries from individuals of different ages, using a polymerase chain reaction (PCR) assay supported by electron microscopy and immunocytochemistry; (2) to use electron microscopy to examine interactions between $C$ pneumoniae and the cells present in the arterial tissue; (3) to assess the extent to which the data fulfil the criteria for causality.

Methods-At necropsy examination, 35 arterial specimens were taken from 25 subjects. The grade of atheroma was determined macroscopically and microscopically and the tissues coded and examined by the three techniques.
\end{abstract}

Results-Of the 35 specimens, 24 had macroscopic or microscopic atheromatous lesions of varying degree. Twenty two of the 35 specimens were examined by electron microscopy, $C$ pneumoniae-like bodies being found in $11(50 \%)$; seven specimens were examined by the immunocytochemical method, positive staining being detected in three; and all specimens were examined by the PCR technique, 15 (43\%) being PCR positive. Overall, of the 24 specimens with lesions, $17(71 \%)$ were positive by at least one of the three tests, whereas of the 11 specimens without lesions, only one was positive. The positive specimens comprised 10 of 19 aortas, three of six iliac arteries, and one coronary and one pulmonary artery. $C$ pneumoniae was detected in four of six specimens in which there were early changes and in a 20 year old subject. Concerning the 25 subjects, of 17 who had atheromatous arteries, 14 (82\%) were $C$ pneumoniae positive and of the eight who had normal arteries, none was positive.

Conclusions-There is a strong correlation between $C$ pneumoniae and arterial atheromatous lesions. The organism may contribute to the disease process by damaging smooth muscle cells.

(f Clin Pathol 1998;51:812-817)

Keywords: atherosclerosis; Chlamydia pneumoniae

Correspondence to: Dr James Ian Phillips, National Centre for Occupational Health, PO Box 4788, Johannesburg 2000, South Africa; email: jim@ncoh.pwv.gov.za

Accepted for publication 1 June 1998

Chlamydia pneumoniae was first described by Grayston et al in $1986 .{ }^{1}$ In common with the other three species of the genus Chlamydia, it is a pathogen. It causes upper respiratory tract infections and is estimated to be responsible for up to $10 \%$ of community acquired pneumonia. $^{2}$

Seroepidemiological studies in several countries have shown the incidence of IgG antibodies to $C$ pneumoniae to be in excess of $50 \%$ and higher in men than in women. ${ }^{2}$ The interpretation of these studies is that the majority of the population has been exposed to the organism. Epidemiological studies have also shown an association of seropositivity for $C$ pneumoniae with coronary heart disease $\mathrm{e}^{3-9}$ and with carotid artery disease. ${ }^{10}$ These findings have been reviewed by Jackson and Grayston. ${ }^{11}$

$C$ pneumoniae was first detected by Shor et $a l,{ }^{12}$ using electron microscopy, in atheromatous lesions of the coronary artery obtained at necropsy from South African patients. Subsequent studies from several centres in different parts of the world have shown the presence of $C$ pneumoniae in both postmortem and surgically obtained lesions derived from the aorta, carotid, coronary, iliac, femoral, and popliteal arteries. ${ }^{11-21}$ Recently, viable $C$ pneumoniae organisms were isolated from atherosclerotic coronary ${ }^{22}{ }^{23}$ and carotid ${ }^{24}$ arteries.

In view of the enormous morbidity and mortality caused worldwide by atherosclerosis, and the lack of agreement about its aetiology, ${ }^{25}$ the association with $C$ pneumoniae is potentially of great importance. As $C$ pneumoniae is a known human pathogen, the possibility of a contributory or causative role has to be considered. However, elucidating whether $C$ pneumoniae initiates, contributes to, or is incidental to atherogenesis is a difficult "chicken or egg" problem. Ong et al have suggested that looking for $C$ pneumoniae using the polymerase chain reaction (PCR) in normal tissue and in arteries with early and advanced atheromatous lesions would be a sensible approach. ${ }^{19}$ Another approach would be to examine the interactions of $C$ pneumoniae using the electron microscope to assess cell damage. A further approach would be to apply the criteria which determine whether an association is causal, as proposed by Hill. ${ }^{26}$ With these issues in mind, we have sought evidence of the existence of $C$ pneumoniae in a spectrum of atheromatous lesions in different types of arteries from individuals of different ages, using a PCR assay, supported by electron microscopy and immunocytochemistry. In addition, electron microscopy was used to examine interactions between $C$ pneumoniae and the cells present in the arterial tissue.
Methods

Arterial tissue was obtained at necropsy examination from the aorta, carotid, cerebral, coronary, femoral, iliac, and pulmonary arter- 
Table 1 Details of subjects and specimens examined

\begin{tabular}{|c|c|c|c|c|c|c|c|c|}
\hline No & Age & Cause & Artery & Macro & Micro & $E M$ & $P C R$ & $I C$ \\
\hline 1 & 26 & Trauma & Aorta & 0 & 0 & - & - & - \\
\hline 2 & 70 & Nat & Aorta & 2 & 2 & + & + & + \\
\hline 3 & 20 & Trauma & Aorta & 1 & 1 & - & - & - \\
\hline $4 a$ & 26 & Trauma & Aorta & 1 & 1 & - & - & - \\
\hline $4 \mathrm{~b}$ & & & & 0 & 0 & - & - & - \\
\hline 5 & 86 & CCF & Aorta & 3 & 3 & + & + & $\mathrm{n} / \mathrm{r}$ \\
\hline $6 a$ & 37 & Trauma & Iliac & 2 & 2 & + & + & + \\
\hline $6 \mathrm{~b}$ & & & Iliac & 2 & 2 & $\mathrm{n} / \mathrm{r}$ & - & $\mathrm{n} / \mathrm{r}$ \\
\hline $6 c$ & & & Iliac & 2 & 2 & $\mathrm{n} / \mathrm{r}$ & + & $\mathrm{n} / \mathrm{r}$ \\
\hline $7 \mathrm{a}$ & 57 & MI & Iliac & 2 & 2 & + & - & $\mathrm{n} / \mathrm{r}$ \\
\hline $7 \mathrm{~b}$ & & & Iliac & 2 & 2 & $\mathrm{n} / \mathrm{r}$ & - & $\mathrm{n} / \mathrm{r}$ \\
\hline $7 \mathrm{c}$ & & & Iliac & 2 & 2 & $\mathrm{n} / \mathrm{r}$ & - & $\mathrm{n} / \mathrm{r}$ \\
\hline $8 \mathrm{a}$ & 75 & Pneumo & Aorta & 2 & 2 & + & - & + \\
\hline $8 b$ & & & Carotid & 0 & 0 & $\mathrm{n} / \mathrm{r}$ & - & $\mathrm{n} / \mathrm{r}$ \\
\hline $8 \mathrm{c}$ & & & Carotid & 3 & 3 & $\mathrm{n} / \mathrm{r}$ & + & $\mathrm{n} / \mathrm{r}$ \\
\hline $9 a$ & 73 & COPD & Carotid & 2 & 2 & + & + & $\mathrm{n} / \mathrm{r}$ \\
\hline $9 b$ & & & Carotid & 0 & 0 & $\mathrm{n} / \mathrm{r}$ & + & $\mathrm{n} / \mathrm{r}$ \\
\hline $9 \mathrm{c}$ & & & Femoral & 2 & 2 & $\mathrm{n} / \mathrm{r}$ & - & $\mathrm{n} / \mathrm{r}$ \\
\hline $10 \mathrm{a}$ & 79 & Nat & Aorta & 2 & 2 & + & + & $\mathrm{n} / \mathrm{r}$ \\
\hline $10 \mathrm{~b}$ & & & & 2 & 2 & $\mathrm{n} / \mathrm{r}$ & + & $\mathrm{n} / \mathrm{r}$ \\
\hline 11 & 0 & Trauma & Aorta & 0 & 0 & - & - & $\mathrm{n} / \mathrm{r}$ \\
\hline 12 & 25 & Trauma & Carotid & 0 & 0 & - & - & $\mathrm{n} / \mathrm{r}$ \\
\hline 13 & 25 & Trauma & Aorta & 0 & 0 & - & - & $\mathrm{n} / \mathrm{r}$ \\
\hline 14 & 30 & Trauma & Aorta & 0 & 0 & - & - & $\mathrm{n} / \mathrm{r}$ \\
\hline 15 & 28 & Trauma & Aorta & 1 & 1 & - & - & $\mathrm{n} / \mathrm{r}$ \\
\hline 16 & 34 & Trauma & Aorta & 1 & 1 & + & + & $\mathrm{n} / \mathrm{r}$ \\
\hline 17 & 24 & Trauma & Cerebral & 0 & 0 & - & - & $\mathrm{n} / \mathrm{r}$ \\
\hline 18 & 52 & Trauma & Coronary & 2 & 2 & + & + & $\mathrm{n} / \mathrm{r}$ \\
\hline 19 & 40 & Trauma & Aorta & 1 & 1 & + & + & $\mathrm{n} / \mathrm{r}$ \\
\hline 20 & 30 & Trauma & Aorta & 0 & 0 & - & - & $\mathrm{n} / \mathrm{r}$ \\
\hline 21 & 22 & Trauma & Aorta & 0 & 0 & - & - & $\mathrm{n} / \mathrm{r}$ \\
\hline 22 & $?$ & Nat & Aorta & 2 & 2 & $\mathrm{n} / \mathrm{r}$ & + & $\mathrm{n} / \mathrm{r}$ \\
\hline 23 & ? & Nat & Cerebral & 3 & 3 & $\mathrm{n} / \mathrm{r}$ & - & $\mathrm{n} / \mathrm{r}$ \\
\hline 24 & $?$ & $?$ & Pulmonary & 2 & 2 & $\mathrm{n} / \mathrm{r}$ & + & $\mathrm{n} / \mathrm{r}$ \\
\hline 25 & 28 & Trauma & Aorta & 0 & 1 & $\mathrm{n} / \mathrm{r}$ & + & $\mathrm{n} / \mathrm{r}$ \\
\hline
\end{tabular}

?, unknown; +, positive; -, negative; CCF, congestive cardiac failure; COPD, chronic obstructive pulmonary disease; EM, electron microscopy; IC, immunocytochemistry; Macro, macroscopic grade; MI, myocardial infarction; Micro, microscopic grade; Nat, natural causes; $\mathrm{n} / \mathrm{r}=$ no result; PCR, polymerase chain reaction; Pneumo, pneumonia.

ies. To reduce the risk of chlamydial DNA cross contamination during dissection, usually only one artery was collected from each subject (table 1).

The cause of death in most cases was trauma. The 35 tissue samples were from 25 males with an age range from newborn to 86 years. Collection of tissue was between 12 and 36 hours after death. The 25 subjects were examined consecutively at necropsy by one pathologist.

At collection, tissue was noted to be macroscopically normal or affected by atheroma, the degree being graded as follows: grade 0 , no visible lesion; grade 1, fatty streak; grade 2, fibrolipid plaque; grade 3, advanced lesion with fibrosis, calcification, ulceration, or haemorrhage.

Each specimen was given a code number and divided into three, one portion being frozen and stored at $-70^{\circ} \mathrm{C}$ for PCR studies. A second portion was fixed in a solution of $10 \%$ phosphate buffered formalin for histology, and a third portion was fixed in a $2.5 \%$ phosphate buffered glutaraldehyde solution for electron microscopy. Each tissue sample was given a coded number and examined by a histopathologist, electron microscopist, and staff of the PCR laboratory, none of whom had access to any specimen information other than a coded number.

Tissue collected in buffered formalin was left to fix for 48 hours and processed routinely before being embedded in wax and sectioned at $5 \mu \mathrm{m}$. Sections were stained with haematoxylin and eosin and Masson's trichrome technique.
The presence and degree of atheroma of the intima was assessed by light microscopy and graded as follows: grade 0, no lesion; grade 1, smooth muscle cell damage, macrophage and foam cell infiltration; grade 2 , central necrotic area with overlying fibrosis; grade 3 , dense fibrosis, calcification, ulceration, neovascularisation, or haemorrhage.

For electron microscopy, the arterial tissue was processed by a standard technique, ${ }^{27}$ sectioned, and stained with lead citrate and uranyl acetate. Semithin, $1 \mu \mathrm{m}$ sections were stained with Azure 2 for comparison with sections for light microscopy. ${ }^{28}$ A Jeol 1200 EX 2 instrument was used to examine $90 \mathrm{~nm}$ sections on 100 mesh copper grids. Component cells and the matrix of the arteries were identified and the presence of organisms with chlamydial morphology was noted.

Additional sections from the wax blocks used to examine the morphology and grade the degree of atheroma were stained using the chlamydia genus-specific CF-2 antibody according to the immunoperoxidase method of Grayston et al..$^{20}$

The tissue samples for the PCR assay, identifiable only by code numbers, were sent by courier in a frozen condition from Johannesburg to London, where they were stored immediately in liquid nitrogen. The DNA extractions and PCR assays were performed according to the method of Ong et al. ${ }^{19}$ When DNA was extracted from the tissues, a negative control-comprising a tube of extraction buffer only-was processed in an identical manner. Each batch of samples in the PCR cycle was accompanied by a negative control, in which water was substituted for the tissue DNA fragments, and a positive control, to which was added sufficient $C$ pneumoniae DNA for the detection of 10 organisms. The first round PCR primers used spanned bases 1053 to 1076 and 1518 to 1540 of the major outer membrane protein (MOMP) gene. The second round primers spanned bases 1053 to 1076 and bases 1254 to 1280 of the MOMP gene. Samples which gave a positive result were confirmed by Southern blot analysis, using a 30 base pair oligonucleotide probe based between the DNA sequences of the two second round primers. The 30 base pair probe spanned bases 1106 to 1135 of the MOMP gene. Samples that gave a negative PCR result were retested for any inhibitors to the PCR assay by seeding an aliquot of the sample DNA with $100 \mathrm{fg}$ of $C$ pneumoniae DNA and repeating the assay. To minimise aerosol contamination, the DNA extraction from the tissue samples was carried out in a laminar flow cabinet in a different room from that used for the PCR assay. Mixing of the pre-PCR reagents and the addition of the DNA aliquot were carried out in separate cabinets. In the second round PCR, the already amplified first round DNA was added in a further laminar flow cabinet in a different room from that used for mixing of pre-PCR reagents and the addition of sample DNA. All cabinets were swabbed with methanol and irradiated with ultraviolet light for 30 minutes before use. 


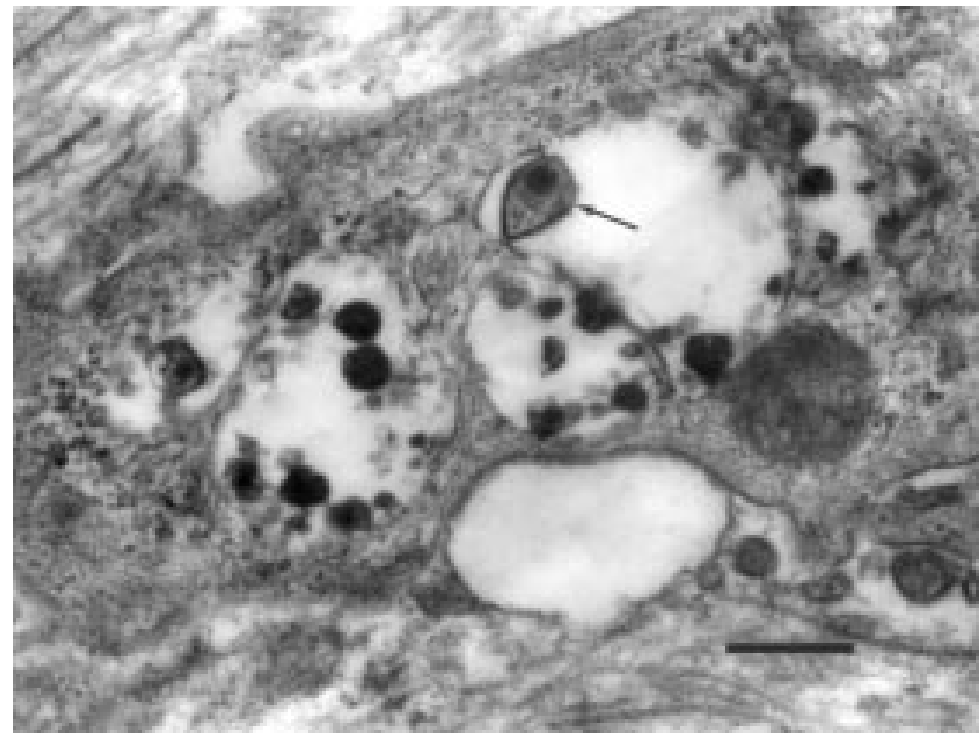

Figure 1 Transmission electron micrograph of an atheromatous arterial wall. Elementary bodies of Chlamydia pneumoniae in vacuoles within a smooth muscle cell. The organisms appear pear shaped in some profiles (arrowed) and contain a central, electron-dense core. The scale bar represents $300 \mathrm{~nm}$.

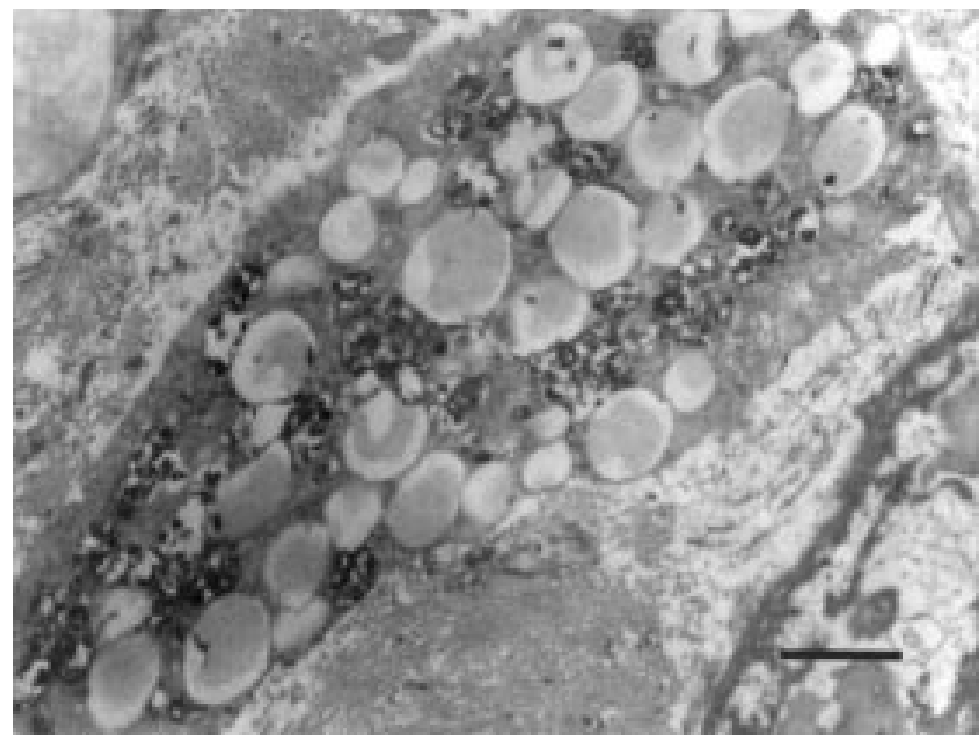

Figure 2 Transmission electron micrograph of a foam cell in an area of atheroma within an artery. The foam cell is identified as a smooth muscle cell full of lipid droplets and vacuoles containing Chlamydia pneumoniae. The scale bar represents $1 \mu \mathrm{m}$.

On completion of all the laboratory investigations, the specimen code number and data were revealed to allow analysis of the data.

\section{Results}

MACROSCOPIC AND MICROSCOPIC LESIONS Of the 35 specimens, 23 were found to have macroscopic lesions: five of grade 1,14 of grade 2, and four of grade 3. Microscopic examination of the specimens showed 24 to have lesions: six of grade 1, 14 of grade 2, and four of grade 3. Thus one macroscopically normal specimen, an aorta from patient No 25, was seen to have a grade 1 microscopic lesion (table 1).

ELECTRON MICROSCOPY

Twenty two specimens were suitable for examination by electron microscopy. Some specimens were not suitable either because of calci- fication, which rendered the tissue impossible to section, or because of failure to orientate the tissue correctly. Structures similar in morphology and size to those of elementary bodies of $C$ pneumoniae were detected in 11 of the specimens. They comprised membrane bound, often pear shaped, 100 to $300 \mathrm{~nm}$ particles, containing an electron-dense core measuring up to $100 \mathrm{~nm}$ diameter (fig 1) and were identified in smooth muscle cells, in foam cells, and in the extracellular debris of atheromatous lesions. The $C$ pneumoniae-like organisms were observed only in areas of tissue damage, and smooth muscle cells containing them were always altered pathologically. The changes observed were vacuolation of the cytoplasm with concurrent reduction in myofilaments and an accumulation of cytoplasmic lipid (fig 2).

\section{IMMUNOCYTOCHEMISTRY}

There was consistent background staining in all but seven of the 35 specimens examined, and this staining could not be completely extinguished by routine blocking techniques. ${ }^{29}$ As a result, the histopathologist was unable to interpret the immunocytochemically stained sections from 28 specimens. Therefore, only seven specimens were assessed by immunocytochemistry; in these, positive staining - clearly distinguishable from any background staining - was detected in three. The positive staining was observed in smooth muscle cells and foam cells and occasionally in the central necrotic core region.

PCR ASSAY

All the 35 specimens were subjected to analysis by the PCR and 15 were positive for $C$ pneumoniae.

CORRELATION OF THE RESULTS OF THE VARIOUS TESTS

Of the 22 specimens examined by electron microscopy, the result of the PCR assay was in agreement in 19. Eight were positive by both tests, 11 were negative by both tests, and three were positive by electron microscopy but negative by the PCR assay. Of the seven specimens examined by immunocytochemistry, the result of electron microscopy was in agreement in six specimens, as was the result of the PCR assay. Overall, of the 35 specimens examined, 18 were positive by at least one of the methods employed. When the 25 subjects rather than specimens are considered, 14 of the 17 who had atheromatous arteries had vessels that were $C$ pneumoniae positive, whereas none of the eight who had normal arteries was positive.

TYPE OF VESSEL AND OCCURRENCE OF

C PNEUMONIAE

Seven different arteries were represented. Of 19 aortas examined, 10 were positive for $C$ pneumoniae by at least one of the methods employed. Of six iliac arteries examined, three were positive; of five carotid arteries examined, three were positive, as were one coronary and one pulmonary artery. Two cerebral arteries and one femoral artery were negative. 
GRADE OF LESION AND OCCURRENCE OF C PNEUMONIAE

On microscopic examination, one of the macroscopically normal aorta specimens, from patient No 25, was seen to have a grade 1 lesion. $C$ pneumoniae was demonstrated in this lesion by the PCR assay. Of the 24 subjects whose specimens had macroscopic or microscopic evidence of a lesion, $C$ pneumoniae was detected in 17: in four of the six grade 1 lesions, 11 of the 14 grade 2 lesions, and two of the four grade 3 lesions. Eleven of the specimens had no lesion by macroscopic or microscopic assessment. Of these, only one was positive for $C$ pneumoniae, in this case by the PCR assay. This tissue sample was from a normal area between atheromatous lesions in the carotid artery of a 73 year old man (patient No 9b). Unfortunately, owing to failure to orientate this specimen correctly, this area could not be examined by electron microscopy to determine whether there was any cell damage.

\section{AGE OF SUBJECT AND OCCURRENCE OF}

C PNEUMONIAE

The age of three of the subjects was not available. Of the remaining 22, 10 were less than 30 years old. Four of these had grade 1 atheromatous lesions, two of which were $C$ pneumoniae positive. Of the 12 subjects who were 30 or more years old, 10 had atheromatous lesions, eight of grade 2 or 3, and all 10 were confirmed $C$ pneumoniae positive.

\section{Discussion}

We are confident that the measures taken to prevent cross contamination of arteries by chlamydial DNA during their collection and processing means that the results obtained by use of the PCR assay are not spurious. Immuno-electronmicroscopy was not used to identify the particles seen, but their structure and size was compatible with the elementary bodies of $C$ pneumoniae. Background staining made the interpretation of the results of immunocytochemistry difficult for all but seven samples. Such staining was a problem also encountered by Ong et $a l .{ }^{19}$ Nevertheless, where interpretation was possible, the agreement of the results obtained by immunocytochemistry with those of the PCR assay and electronmicroscopy indicates that the results of immunocytochemistry are not non-specific and caused, as has been suggested, ${ }^{30}$ by cross reactivity of the chlamydial antibody with a diseased tissue component. Overall, there was good agreement between the results of the three independent techniques. Based on these, the important observations in this study are as follows: first, the detection of $C$ pneumoniae in $71 \%$ of arterial atheromatous lesions, in keeping with the results of some previous studies in which the organism has been detected in $60 \%$ to $100 \%$ of lesions ${ }^{13}{ }^{18}$; second, the detection, for the first time, of the organism in a lesion of the pulmonary artery (the organism has now been described in this artery and in lesions of the aorta, carotid, coronary, femoral, popliteal, ${ }^{21}$ and iliac arteries); third, the occurrence of $C$ pneumoniae only in areas of tissue damage as shown by electron microscopy and immunocytochemistry; and, finally, the finding that minimal lesions are $C$ pneumoniae positive as often as severe lesions.

Whether $C$ pneumoniae has a causal role in atheroma is the important "chicken or egg" issue. C pneumoniae has been isolated by culture from atheromatous arteries ${ }^{22-24}$; however, the organism appears difficult to culture consistently, which makes the fulfilment of Koch's postulates difficult to achieve. However, the question of association or causation has been addressed by $\mathrm{Hill}^{26}$ who highlighted nine aspects to consider before deciding on an interpretation of causality. These are concerned with an examination of the association in terms of its strength, consistency, specificity, temporality, plausibility, coherence, analogy, biological gradient, and experimental evidence. We shall consider them in the light of existing data and those provided by this study.

Apart from one report of failure to detect $C$ pneumoniae in coronary artherectomy specimens, ${ }^{31}$ which has been criticised by Jackson et $a l,^{32}$ there is a strong positive and consistent association between $C$ pneumoniae and arterial atheromatous lesions. This was evident in our present study and in reports from several laboratories in different countries based on the use of the PCR assay ${ }^{12-192133}$ and culture. ${ }^{22-24}$

In relation to specificity, whereas cytomegalovirus has been detected in both normal and atheromatous arteries, ${ }^{15}$ C pneumoniae has been found more specifically in atheromatous lesions in this and other studies. ${ }^{33}$

To fulfil the criterion of temporality, the organism must be found in the earliest lesions. It was clear in this study that the existence of $C$ pneumoniae in arteries was related to the age of the subjects. Below the age of 30 years, fewer subjects had atheromatous lesions and those that had, had the less severe lesions. Nevertheless, $C$ pneumoniae was detected in half of them. Thus $C$ pneumoniae has been documented here and elsewhere in fatty streaks ${ }^{12}$ which are considered to be the earliest manifestation of atheroma. Indeed, in subject No 25, a 28 year old, a lesion in the aorta was noted only microscopically, but $C$ pneumoniae was detected by the PCR technique. Overall, our observations are in keeping with the findings of Kuo et $a l,{ }^{15}$ who demonstrated $C$ pneumoniae in the coronary arteries of young adults (15 to 35 years old).

Is a causal association plausible? The answer would seem to be in the affirmative. $C$ pneumoniae is a pathogenic organism which has been shown in vitro to be capable of infecting aortic smooth muscle cells, endothelial cells, and macrophages, ${ }^{3435}$ all of which are involved in atherogenesis. ${ }^{36}$ Furthermore, the results of seroepidemiological studies have shown that infection with $C$ pneumoniae is common, ${ }^{2}$ occurring at an early age and at intervals throughout life and-like coronary heart disease-more commonly in males. ${ }^{2}$

Would a causal role for $C$ pneumoniae be coherent with existing knowledge about atherogenesis? For some time there has been an 
accepted response to injury hypothesis to explain atherogenesis, and microorganisms, including viruses, have been proposed as initiators of injury. ${ }^{36}{ }^{37}$ The electronmicroscopic findings suggest that $C$ pneumoniae may be contributing to the disease process by damaging smooth muscle cells. Smooth muscle cells containing $C$ pneumoniae show vacuolation, loss of myofilaments and an accumulation of lipid. The resultant foam cell is a characteristic feature of atheroma. ${ }^{37}$ In addition, an analogy has been drawn between $C$ pneumoniae and $C$ trachomatis, the latter causing chronic, fibrotic, and necrotic lesions in trachoma and lymphogranuloma venereum. ${ }^{38}$ Recent reports of an association between $\mathrm{C}$ reactive protein, interleukin 6 , and coronary heart disease support the concept of an underlying inflammatory process, such as a chronic infection, playing a role in atherogenesis. ${ }^{39-41}$

There are no data concerning a biological gradient to fulfil Hill's criterion, but preliminary experimental evidence from mouse and rabbit models ${ }^{42}{ }^{43}$ indicate that infection with $C$ pneumoniae can produce an atherosclerotic lesion in the aorta.

With regard to experimental evidence, eradication experiments have been suggested. ${ }^{1920}$ Some data have been published on the effects of antichlamydial agents on patients at risk for coronary heart disease, and these initial results appear to show a beneficial effect associated with antibiotic administration. ${ }^{44}{ }^{45}$ In the rabbit model, treatment with an antichlamydial agent prevents the development of atherosclerosis. ${ }^{43}$

In conclusion, we have confirmed a strong positive association between $C$ pneumoniae and atheroma. The extent of the association has been expanded to include the pulmonary artery. $C$ pneumoniae has been demonstrated in the earliest lesions of atheroma and in subjects as young as 20 years. The observation that infected smooth muscle cells in the arterial wall become vacuolated, lipid filled, and contribute to the foam cell population is consistent with a possible causal role for $C$ pneumoniae in the development of atheromatous lesions. Indeed, from the work in this and other studies, Hill's criteria for causation have been fulfilled to a large extent. However, unequivocal evidence is still lacking. If $C$ pneumoniae existed only in the older lesions then no case could be made for it as an initiator of atheroma. Demonstration of the organism in subjects as young as 20 years and in the earliest lesions of atheroma is consistent with it having a causal role. Unfortunately, it is still not possible to establish whether $C$ pneumoniae predates and initiates an early lesion or infiltrates an early lesion after it has begun to develop. Resolution of this conundrum may lie in the outcome of preventive measures, most notably antibiotic treatment. Initial results in humans ${ }^{44}{ }^{45}$ treated with antichlamydial agents are encouraging. The prevention of atherosclerosis in rabbits infected with $C$ pneumoniae and treated with antibiotics ${ }^{43}$ strengthens the aetiological link between $C$ pneumoniae and atherosclerosis. Data from more clinical trials are needed, along with an examination of the interaction of $C$ pneumoniae with arterial tissue.

We wish to acknowledge the technical assistance of Mrs Jemima Cantrell and Mrs Amina Touh-Touh.

1 Grayston JT, Kuo C-C, Wang SP, et al. A new Chlamydia psittaci strain, TWAR, isolated from acute respiratory tract nfections. N Engl f Med 1986;315:161-8.

2 Grayston JT. Infections caused by Chlamydia pneumoniae strain TWAR. Clin Infect Dis 1992;15:757-63.

3 Saikku P, Mattila K, Nieminen MS, et al. Serological evidence of an association of a novel Chlamydia, TWAR, with chronic coronary heart disease and acute myocardial infarction. Lancet 1988;ii:983-6.

4 Leinonen M, Linnanmaki E, Mattila K, et al. Circulating immune complexes containing chlamydial lipopolysaccharide in acute myocardial infarction. Microb Pathog 1990;9:

5 Saikku P, Leinonen M, Tenkanen L, et al. Chronic Chlamydia pneumoniae infection as a risk factor for coronary heart disease in the Helsinki heart study. Ann Intern Med 1992;116:273-8.

6 Linnanmaki E, Leinonen M, Mattila K, et al. Chlamydia pneumoniae specific circulating immune complexes in patients with chronic coronary heart disease. Circulation 1993;87:1130-4.

7 Thom DH, Wang S-P, Grayston JT, et al. Chlamydia pneumoniae strain TWAR antibody and angiographically demonstrated coronary heart disease. Arterioscler Thromb 1991; 11:547-51.

8 Thom DH, Grayston JT, Siscovick DS, et al. Association of prior infection with Chlamydia pneumoniae and angiographically demonstrated coronary artery disease. $7 A M A$ 1992;268:68-72.

9 Patel P, Kendall MA, Carrington D, et al. Association of Helicobacter pylori and Chlamydia pneumoniae infections with coronary heart disease. BMF 1995;311:711-14.

10 Melnick S, Shahar E, Folsom A, et al. Past infection by Chlamydia pneumoniae strain TWAR and asymptomatic carotid atherosclerosis. $\mathscr{F A M A}$ 1993;95:499-504.

11 Jackson L, Grayston T. Chlamydia pneumoniae and Mycoplasma pneumoniae infections. Curr Opin Infect Dis 1996;9:89-93

12 Shor A, Kuo C-C, Patton DL. Detection of Chlamydia pneumoniae in the coronary artery atheroma plaque. $S$ Afr Med f 1992;82:158-61

13 Kuo C-C, Shor A, Campbell LA, et al. Demonstration of Chlamydia pneumoniae in atherosclerotic lesions of coronary arteries. I Infect Dis 1993;167:841-9.

14 Kuo C-C, Gown AM, Benditt EP, et al. Detection of Chlamydia pneumoniae in aortic lesions of atherosclerosis by immunocytochemical stain. Arterioscler Thromb 1993; 13:1501-4.

15 Kuo C-C, Grayston JT, Campbell LA, et al. Chlamydia pneumoniae (TWAR) in coronary arteries of young adults (15-35 years old). Proc Natl Acad Sci USA 1995;92:691114.

16 Campbell LA, O’Brien ER, Cappuccio AL, et al. Detection of Chlamydia pneumoniae (TWAR) in human coronary artherectomy tissue. $\mathcal{F}$ Infect Dis 1995;172:585-8.

17 Ouchi K, Fujii B, Kamamoto Y, et al. Detection of Chlamydia pneumoniae in atherosclerotic lesions of coronary arteries and large arteries [abstract]. 35th Interscience Conference on Antimicrobial Agents and Chemotherapy, K37).

18 Juvonen J, Juvonen T, Laurila A, et al. Demonstration of Chlamydia pneumoniae in the walls of abdominal aortic aneurysms [abstract]. Third International Congress on the Macrolides, Azalides and Streptogramins. Lisbon, 24-26 Macrolides, Azal

19 Ong G, Thomas BJ, Mansfield AO, et al. Detection and widespread distribution of Chlamydia pneumoniae in the vascular system and its possible implications. I Clin Pathol 1996;49:102-6.

20 Grayston JT, Kuo C-C, Coulson AS, et al. Chlamydia pneumoniae (TWAR) in atherosclerosis of the carotid artery. Circulation 1995;92:3397-400.

21 Kuo C-C, Coulson AS, Campbell LA, et al. Detection of Chlamydia pneumoniae in atherosclerotic plaques in the walls of arteries of lower extremities from patients undergoing bypass operation for arterial obstruction. $\mathcal{F}$ Vasc undergoing bypass op $1997 ; 26: 29-31$.

22 Ramirez JA, the Chlamydia pneumoniae/Atherosclerosis Study Group. Isolation of Chlamydia pneumoniae from the coronary artery of a patient with coronary atherosclerosis. Ann Intern Med 1996;125:979-82.

23 Maas M, Krause E, Kruger S, et al. Coronary arteries harbour viable Chlamydia pneumoniae. Fourth international symposium on modern concepts in endocarditis and cardiovascular infections [abstract]. Yverdon-LesBaines, Switzerland, May 1997 (abstract 101).

24 Jackson LA, Campbell LA, Kuo C-C, et al. Isolation of Chlamydia pneumoniae from a carotid endarterectomy specimen. F Infect Dis 1997;176:292-5.

25 Woolf N. Pathology of atherosclerosis. London: Butterworth, 1982 .

26 Hill AB. The environment and disease: association or causation? Proc R Soc Med 1965;58:295-300. 
27 Phillips JI, Isaacson C, Carman H. Ochronosis in black South Africans who used skin lighteners. Am $\mathcal{F}$ DermatSouth Africans who use
opathol 1986;8:14-21.

28 Phillips JI. Lack of cilia and squamous metaplasia in upper respiratory tract biopsies from children. S Afr Med $\mathcal{F} 1989$; 76:355-7.

29 Nadji M. Immunoperoxidase techniques. Am $f$ Dermatopathol 1986;8:32-6.

30 Wissler RW. Significance of Chlamydia pneumoniae (TWAR) in atherosclerotic lesions. Circulation 1995;92 3376.

31 Weiss SM, Roblin PM, Gaydos CA, et al. Failure to detect Chlamydia pneumoniae in coronary atheromas of patients undergoing atherectomy. F Infect Dis 1996;173:957-62.

32 Jackson LA, Campbell LA, Kuo C-C, et al. Detection of Chlamydia pneumoniae in atheroma specimens. F Infect Dis 1996;174:893-6.

33 Jackson LA, Campbell LA, Schmidt RA, et al. Specificity of detection of Chlamydia pneumoniae in cardiovascular detection of Chlamydia pneumoniae in

34 Knoebel E, Vijayagopal P, Figueroa JE, et al. In vitro infection of smooth muscle cells by Chlamydia pneumoniae. Infect Immun 1997; 65:503-6.

35 Gaydos CA, Summersgill JT, Sahney NN, et al. Replication of Chlamydia pneumoniae in human macrophages, endothelial cells and aortic artery smooth muscle cells. Infect Immun 1996;64:1614-20.

36 Ross R. The pathogenesis of atherosclerosis: a perspective for the 1990's. Nature 1993;362:801-9.
37 Hajiar DP, Nicholson AC. Atherosclerosis. Am Scientist 1995;83:460-7.

38 Blanchard T, Bailey R, Holland M, et al. Chlamydia pneumoniae and atherosclerosis. Lancet 1993;341:825.

39 Maseri A, Biasucci LM, Liuzzo G. Inflammation in ischaemic heart disease. BMF 1996;312:1049-50.

40 Mendall MA, Patel P, Ballam L, et al. C-reactive protein and its relation to cardiovascular risk factors: a populationits relation to cardiovascular risk factors: a populatio
based cross-sectional study. BMF 1996;312:1061-5.

41 Ridker PM, Cushman M, Stampfer MJ, et al. Inflammation, aspirin, and the risk of cardiovascular disease in apparently healthy men. N Engl F Med 1997;336:973-9.

42 Moazed TC, Kuo C-C, Grayston JT, et al. Murine models of Chlamydia pneumoniae infection and atherosclerosis. $f$ Infect Dis 1997;175:883-90.

43 Muhlestein JB, Anderson JL, Hammond EH, et al. Infection with Chlamydia pneumoniae accelerates the development of atherosclerosis and treatment with azithromycin prevents it in a rabbit model. Circulation 1998;97:633-6.

44 Gupta S, Leathan EW, Carrington D, et al. Elevated Chlamydia pneumoniae antibodies, cardiovascular events and azithromycin in male survivors of myocardial infarction. Circulation 1997;96:404-7.

45 Gurfinkel E, Bozovich G, Daroca A, et al. and ROXIS study group. Randomised trial of roxithromycin in non-Q-wave coronary syndromes: Roxis pilot study. Lancet 1997;350: $404-7$. 